\title{
PELOS CAMINHOS DO DIÁLOGO ABERTO: REFLEXÕES SOBRE APRENDER, PRATICAR E FORMAR PROFISSIONAIS NO CONTEXTO DA SAÚDE MENTAL NO BRASIL
}

\author{
THROUGH THE PATHWAYS OF OPEN DIALOGUE: REFLECTIONS ON \\ LEARNING, PRACTICING AND TRAINING PROFESSIONALS IN THE CONTEXT \\ OF MENTAL HEALTH CARE IN BRAZIL
}

CECÍLIA CRUZ VILLARES

Instituto NOOS, São Paulo/ SP, Brasil
RESUMO: Este texto apresenta a abordagem do Diálogo Aberto a partir de reflexões e questões de meu percurso de aprendizado, prática e ensino em saúde mental. Utilizei como material de referência os artigos sobre o tema mais relevantes em meu percurso de formação, entrelaçados com anotações de aulas e workshops, diários reflexivos e rascunhos de projetos engavetados. Escrevi este texto tendo em mente o crescente interesse de profissionais brasileiros que atuam na área da saúde mental em conhecer os princípios do Diálogo Aberto, interesse este que parece refletir o reconhecimento da abrangência e relevância desta abordagem para as questôes atuais do sistema de saúde mental em nosso país. Meu intento é tecer algumas considerações úteis para aqueles que desejam começar a conhecer o Diálogo Aberto, que tenham perguntas sobre como "tornar-se dialógico" na vida e na prática clínica, e queiram pensar como princípios dialógicos podem contribuir para as práticas correntes no campo da Saúde Mental.

PALAVRAS-CHAVE: Diálogo aberto; Dialogia; Saúde mental; Aprendizado; Reflexão.
ABSTRACT: This paper presents the Open Dialogue approach from reflections and questions out of a personal path of learning, teaching and practice in mental health. For this purpose, I drew on sources from articles relevant to the subject, interwoven with workshops and class notes, journals and drafts of shelved projects. I wrote this text to address the growing interest of Brazilian professionals working in the field of mental health to get to know the principles of Open Dialogue, which seems to reflect the recognition of the scope and relevance of this approach to current issues of the mental health system in our country. I hope to bring some useful considerations to those who wish to be introduced to Open Dialogue, who have questions about "becoming dialogical" in life and clinical practice, and who want to discuss how dialogical principles can contribute to current practices in the field of Mental health.

KEYWORDS: Open Dialogue; Dialogic; Mental Health; Learning Processes; Reflexion.
Recebido em: 30/09/2019 Aprovado em: 30/10/2019

\section{INTRODUÇÃo}

Este texto propõe uma conversa reflexiva sobre aprender, praticar e ensinar uma maneira de estar na clínica com pessoas que buscam ajuda para entender e lidar com um problema de saúde mental na família, a abordagem do Diálogo Aberto - um modelo de prática em saúde mental desenvolvido, extensivamente estudado e avaliado desde os anos 1980. Inicialmente implantado numa pequena região da Finlândia, ao longo da última década foi disseminado e adaptado 
em vários países da Europa, Estados Unidos, Austrália e atualmente se expande para alcançar também o Japão e países da América Latina. O Diálogo Aberto propõe um modo de prática em que as decisões sobre o tratamento são construídas coletivamente nas reuniões/sessões nas quais participam profissionais de uma equipe de saúde mental, familiares e/ou pessoas da rede significativa de relações e a pessoa que apresenta um problema grave ou agudo de saúde mental. Os encontros são agendados tão logo a equipe seja contatada e, através de conversas reflexivas, buscam estabelecer um diálogo entre todos, onde a flexibilidade, a polifonia, a continuidade psicológica, a corresponsabilidade e a tolerância à incerteza são alguns dos valores e princípios para a sua realização.

Em 1999, terapeuta ocupacional a meio caminho de um Curso de Formação em Terapia Familiar, em uma mesa redonda em um Congresso ${ }^{1}$, fiz uma apresentação que intitulei: "Terapia Ocupacional: itinerários e discursos”. O propósito da minha fala era levantar algumas questões a respeito da prática da terapia ocupacional através de uma reflexão sobre a identidade desse profissional, examinando alguns dos pressupostos que sustentam a prática e o raciocínio clínico em terapia ocupacional. Naquele momento, eu trabalhava intensamente a minha própria identidade de terapeuta face ao que vinha vivenciando na formação em terapia familiar. Minha fala estava endereçada a colegas terapeutas ocupacionais e alunos presentes no evento, mas respondia primeiramente a questionamentos e inquietações pessoais sobre o meu fazer profissional, sobre ensinar a pensar e atuar em terapia ocupacional na saúde mental.

Eu respondia também à percepção de uma mudança de pressupostos filosóficos iniciada ao estudar a convi- vência familiar na esquizofrenia num projeto acadêmico de cunho etnográfico. No percurso desse estudo surgiram as perguntas que me levaram a buscar uma formação em terapia familiar que, por sua vez, me abriu um universo e novas linguagens que estavam provocando uma profunda transformação na maneira como eu pensava e vivia as relações, tanto pessoais como profissionais. Naquela altura, eu tinha consciência de tal mudança e desejava compartilhar com meus colegas terapeutas ocupacionais alguns aprendizados e questionamentos, bem como apresentar pressupostos que, pensava, poderiam vir a integrar estratégias clínicas em terapia ocupacional mais sintonizadas com uma postura que, naquele momento, eu descrevia como pós-moderna: atenta ao contextual e relacional e à compreensão de uma realidade construída em narrativas compartilhadas, social e historicamente situadas.

Desde então, o texto onde alinhavei as ideias principais daquela apresentação repousou numa pasta chamada "projetos". De tempos em tempos o revisitava, relia, acrescentava algo e voltava a colocá-lo a dormir (ou melhor dizendo, maturar?). Agora, terminando uma segunda formação em Terapia Familiar na Abordagem do Diálogo Aberto, voltei àquele texto. Desta vez, no entanto, não mais para uma conversa solitária com minha narrativa/ história, mas com a intenção de partilhar reflexões sobre os caminhos de aprender, praticar e ensinar (em) saúde mental. Para isso, recorria a outros rascunhos, diários reflexivos e às muitas horas de estudo, prática e reflexão conjunta com os colegas que embarcaram comigo nesta canoa em construção, ${ }^{2}$ como quem escolhe os melhores retalhos para uma boa colcha. Trago também como inspiração inicial para a confecção deste texto o artigo

\begin{abstract}
${ }^{1}$ Mesa redonda "Narrativas em terapia ocupacional" no VI Congresso Brasileiro de Terapia Ocupacional. Lindóia-SP, outubro de 1999.
\end{abstract}

2 Flávia Camargo, Elvis Andrade, Roberto Costard, Denise Liesegang, Leonora Corsini e Ana Luiza Coutinho - obrigada pela confiança, pelas questões, pelo entusiasmo e disponibilidade para formar comigo um time tão prazeroso quanto comprometido. Seguimos em frente (às vezes em zig-zag, é verdade), construindo juntos. 
autoetnográfico de Olson (2015) professora, mentora e supervisora em minha jornada de formação atual. Sua narrativa biográfica de percurso de formação e transformação pessoal foi um dos primeiros textos com o qual "conversei" no início do curso, em 2017, e, nesse sentido, me convidou a um processo de pensar e refletir sobre os caminhos que me levaram ao Diálogo Aberto, sobre meus itinerários na vida e sobre aprender na ação.

$\mathrm{O}$ que me motivou a escrever foi o convite da NPS para relatar a minha experiência no curso do Institute for Dialogic Practices de Nova York, e as vivências e questões a partir das práticas desenvolvidas ao longo desse percurso de formação iniciado em 2017. Preciso dizer que o convite tanto me honrou quanto inicialmente assustou, pela liberdade acompanhada de imensa responsabilidade, pois imediatamente me conectei com a minha exigência de produzir um "bom texto". Pus-me a perguntar: quanto de informação, de conceitos, perguntas e reflexões seriam úteis, necessárias e interessantes? Como escrever um texto mais biográfico que acadêmico e, ainda assim, oferecer informação útil? Como contornar a inevitável autorreferência num texto de base biográfica? E nesse processo de me perguntar, fui percebendo que, para produzir um "bom texto" sobre meu percurso de aprender a Abordagem do Diálogo Aberto, eu precisava arriscar a escrever algo fluido e entranhável como uma boa história de amor.

E por que o amor? Porque só podemos contar as nossas histórias se encontramos um ouvinte atento, curioso, respeitoso e responsivo. Da mesma forma, quando nos colocamos na posição de ouvintes para escutar as histórias dos outros, o fazemos a partir de uma postura dialógica que é necessariamente amorosa. As histórias só existem na presença de alguém que as escute, e nesse sentido o contar histórias é um fenômeno dialógico (Seikkula \& Trimble, 2005). Então, para produzir um texto sobre a experiência de aprender, praticar e ensinar a abordagem dialógica, eu precisava contar um pouco da minha história e convidar leitores interessados nesse diálogo. Portanto, este texto propõe uma conversa e é uma tentativa de responder honradamente a um convite que, imagino, represente um reconhecimento de meu percurso profissional, mas que me convida, principalmente, a falar sobre "aprender fazendo junto".

\section{A ABORDAGEM DO DIÁLOGO ABERTO EM MEU PERCURSO PROFISSIONAL}

A perspectiva dialógica no campo da terapia de família se inscreve numa tradição de terapias narrativas, colaborativas e reflexivas propostas por autores geograficamente distantes - Tom Andersen, na Noruega; Michael White, na Austrália; Harlene Anderson e Harry Goolishian, nos EUA, para citar alguns dos mais influentes - mas afinados em uma postura filosófica comum na compreensão da construção da realidade, das relações, e da função performática da linguagem no contar histórias em contextos relacionais de colaboração para construção de mudança em terapia e práticas comunitárias.

Não sei precisar exatamente quando tomei conhecimento da Abordagem do Diálogo Aberto, mas, ao iniciar a formação em terapia familiar, em 1998, eu já conhecia a "Abordagem Adaptada às Necessidades" (Need Adapted Treatment) de Irjö Alanen (1997), professor finlandês de psiquiatria da Universidade de Turku, que, desde os anos 1970, desenvolveu um 
trabalho de aproximação das práticas psicoterapêuticas no tratamento clínico da esquizofrenia, no escopo do "Finnish National Schizophrenia Project", uma iniciativa de pesquisa visando ao desenvolvimento de melhores cuidados nos transtornos mentais graves na Finlândia. Conheci a abordagem de Alanen através de seu livro: "Schizophrenia: its origins and need-adapted treatment", editado em finlandês na década de 80 e publicado em inglês em 1997. Nessa época, eu estava mergulhada no estudo da convivência familiar na esquizofrenia $e$ integrava um grupo de estudos sobre intervenção familiar com colegas do $\mathrm{PROESQ}^{3}$ que partilhavam comigo o interesse em pensar sobre questões relativas à família para embasar e propor alguma prática mais consistente em nosso serviço. O livro de Alanen nos provocou tanto entusiasmo quanto desilusão, por percebermos a distância de nossas práticas com relação ao que vislumbrávamos como desejável para criar um contexto mais colaborativo na clínica terapêutica com pacientes e familiares. Entretanto, tínhamos bastante liberdade para experimentações, e inspirados pelas ideias de participação das famílias e dos pacientes desde o início do tratamento em reuniões de planejamento, propusemos iniciativas em sintonia com uma clínica baseada em relações mais horizontais entre profissionais e pacientes/famílias.

Como consequência, o PROESQ adotou, por exemplo, a prática de discussão periódica do projeto terapêutico individual pela equipe de profissionais e buscou instituir em seu programa de formação de residentes a prática do diagnóstico idiográfico ${ }^{4}$. Particularmente com relação às famílias, criamos um modelo de grupo de orientação e apoio, os "Seminários Informativos", que desenvolvemos e avaliamos ao longo de quase 20 anos, iniciativa que se desdobrou no projeto "Famílias Parceiras em Saúde Mental", onde pudemos começar a experimentar uma postura de parceria e colaboração que alimentou as primeiras ações do Projeto SOESQ e da ABRE - Associação de Familiares, Amigos e Portadores de Esquizofrenia. (Villares, 2000, 2001, 2006a, 2012).

Documentei a história de como desenvolvemos essas práticas colaborativas com famílias para além do enquadre da clínica, o Projeto SOESQ e a ABRE, em vários textos -alguns publicados na Nova Perspectiva Sistêmica (Assis \& Villares, 2006; Villares, 2006b, 2008; Villares et al., 2013; Villares \& Pimentel, 2015). Aqui quero apenas ressaltar que os familiares e as pessoas com experiência vivida de esquizofrenia que fizeram parte destes projetos são as pessoas com quem mais aprendi a construir práticas colaborativas, diálogo e corresponsabilidade na saúde mental.

Voltando à Finlândia - o projeto da equipe liderada por Alanen foi também uma grande inspiração para Seikkula e seus colegas, que desde que entraram em contato com a maneira de trabalhar da equipe do Hospital de Turku fizeram mudanças importantes em sua prática com pacientes psicóticos no hospital de Keropudas em Tornio, na Lapônia finlandesa. Uma das propostas mais inovadoras de Alanen e seus colaboradores havia sido a instituição das reuniões abertas de planejamento do tratamento, em que os pacientes e seus familiares, ou pessoas significativas de sua rede social, passaram a integrar as discussões e planejamento do tratamento conjuntamente com os profissionais responsáveis desde o primeiro contato com o serviço psiquiátrico. Isso significa que a equipe deixou de fazer reuniões prévias de planejamento e discussão de casos.
${ }^{3}$ PROESQ - Programa de Esquizofrenia da Universidade Federal de São Paulo, onde trabalhei por mais de 30 anos em atividades de clínica, ensino e pesquisa.

${ }^{4}$ Diagnóstico idiográfico é uma proposta de formulação diagnóstica que busca integrar a multiaxialidade proposta pelos sistemas atuais de classificação diagnóstica com uma formulação individual, visando ao desenvolvimento de projetos terapêuticos mais abrangentes. Foi proposto pelo IGDA (International Guidelines for Diagnostic Assessment), um projeto da WPA (World Psychiatric Association) em colaboração com a OMS - Organização Mundial da Saúde. (IGDA/WPA, 2003). 
Essa perspectiva encantou Seikkula e sua equipe, que vislumbraram nela um caminho para aproximar as abordagens psicoterapêuticas individual e de terapia sistêmica aos familiares, e prontamente levaram este e os demais princípios estabelecidos pela Equipe de Turku (Alanen, 1997, 2009) para seu contexto de prática no Hospital de Keropudas.

Os cinco princípios estabelecidos pela Equipe da Alanen em Turku foram:

1. Rápida intervenção após o primeiro contato com o serviço psiquiátrico.

2. Planejamento do tratamento levando em consideração as necessidades singulares de cada pessoa e buscando a integração de abordagens terapêuticas.

3. Atitude terapêutica de todos os profissionais envolvidos no tratamento, em todas as suas etapas.
4. Compreensão do tratamento como um processo contínuo.

5. Follow-up constante do progresso e resultados do tratamento.

A estes cinco princípios, a equipe de Seikkula adicionou posteriormente mais dois - Tolerância à incerteza e Dialogismo - para compor os sete princípios da Abordagem do Diálogo Aberto (Seikkula et al., 2003). Olson, Seikkula e Ziedonis (2014) posteriormente estabeleceram 12 critérios de fidedignidade do Diálogo Aberto na publicação "The key elements of Open Dialogue", criando princípios terapêuticos e parâmetros para apoiar o ensino e a supervisão, a avaliação, a sistematização e a multiplicação da Abordagem do Diálogo Aberto em diversos contextos de práticas nos países onde têm se desenvolvido.

Tabela 1 - 0s sete princípios estruturais e 12 princípios terapêuticos da abordagem do Diálogo Aberto

\begin{tabular}{|c|c|}
\hline Princípios Estruturais & Princípios Terapêuticos \\
\hline Ajuda imediata & Dois (ou mais) terapeutas na reunião \\
\hline Perspectiva de Rede Social & Participação da família e rede \\
\hline Flexibilidade e mobilidade & Uso de perguntas abertas \\
\hline Responsabilidade & Respondendo aos enunciados dos clientes \\
\hline Continuidade psicológica & Enfatizando o momento presente \\
\hline Tolerância à incerteza & Convidando múltiplos pontos de vista \\
\hline Diálogo e polifonia & Uso de um enfoque relacional no diálogo \\
\hline \multirow{5}{*}{} & $\begin{array}{c}\text { Respondendo de forma prática e atenta os } \\
\text { significados }\end{array}$ \\
\cline { 2 - 2 } & $\begin{array}{c}\text { Enfatizando as palavras e histórias dos } \\
\text { clientes, e não os sintomas }\end{array}$ \\
\cline { 2 - 2 } & $\begin{array}{c}\text { Conversa entre profissionais (reflexões) nas } \\
\text { reuniões }\end{array}$ \\
\cline { 2 - 2 } & Sendo transparente \\
\cline { 2 - 2 } & Tolerando a incerteza \\
\cline { 2 - 2 } & \\
\cline { 2 - 2 }
\end{tabular}

Fonte: Adaptado de "The key elements of dialogic practice in open dialogue: fidelity criteria" (M. Olson, J. Seikkula, \& D. Ziedonis), University of Massachusetts Medical School. Worcester, MA. Recuperado de https://medschool.ucsd.edu/som/psychiatry/research/open-dialogue/Documents/keyelementsv1.109022014.pdf 
A história do desenvolvimento do Diálogo Aberto, seus pressupostos teóricos e clínicos, avaliações de efetividade, a articulação com os conceitos de dialogia e polifonia de Bakhtin, bem como indagações e investigações recentes sobre mente relacional e corporificação no diálogo, estão bem documentadas em muitas publicações Bergström et al., 2018; Seikkula, 1994, 2008, 2011; Seikkula et al., 1995, 2003, 2006, 2018; Seikkula e Olson, 2003; von Peter et al., 2019 - para citar algumas. Esta extensiva documentação de seu desenvolvimento, fundamentação teórica, avaliações e desdobramentos nas questões de políticas de saúde mental e direitos humanos vem se construindo coerentemente a partir da proposta inicial de constituir uma maneira de estar, ouvir e participar nas conversas com pacientes e familiares, e de prover princípios para a transformação do próprio sistema psiquiátrico. Este conjunto de experiências e documentação, somado aos esforços de multiplicação da abordagem levados a cabo nos últimos dez anos, tem possibilitado que o Diálogo Aberto seja contemporaneamente uma proposta alternativa de prática integrada em saúde mental que questiona e desafia o discurso dominante fortemente biomédico que se instalou na psiquiatria e nos serviços de saúde mental nas últimas décadas.

Esta foi uma das razões pelas quais me interessei em conhecer o Diálogo Aberto. O percurso de me tornar terapeuta de família foi sempre desafiador, pois nunca deixei de trabalhar como terapeuta ocupacional no Departamento de Psiquiatria de uma Escola Médica ${ }^{5}$. Nesse sentido transitei, nos últimos vinte anos, entre dois universos dissonantes de linguagem e prática, não sem uma dose permanente de conflito e sofrimento. Fui entenden- do que ficar em ambos os lugares era a expressão do desejo de usar minha experiência no mundo acadêmico psiquiátrico para fazer 'alguma diferença', e a abordagem do Diálogo Aberto foi o caminho que encontrei para aproximar o que aprendi com a terapia familiar às práticas na saúde mental mais afinadas com posturas reflexivas e colaborativas.

A maneira como busquei construir essa aproximação foi inicialmente através de disciplinas específicas na formação, tanto na Unifesp como no Instituto Familiae de São Paulo. Nos dois âmbitos de prática e ensino, convidei profissionais em formação a conhecer alguns conceitos fundamentais das práticas construcionistas, dialógicas e colaborativas, e a fazer aproximações com as práticas correntes com famílias nos serviços de saúde mental. $\mathrm{Na}$ Unifesp, o desdobramento mais importante dessa iniciativa está hoje nas práticas afinadas com o Modelo do Recovery ${ }^{6}$ que temos desenvolvido no contexto de uma parceria entre a ABRE e o PROESQ.

No Instituto Familiae, entre 2007 e 2013, coordenamos, Helena Maffei Cruz e eu, o módulo "Família e Transtorno Mental" no Curso de Formação em Terapia Familiar e de Casal, onde começamos a introduzir o Modelo do Diálogo Aberto como um dos temas do programa da disciplina da formação. Nessa época, a Revista NPS publicou dois artigos traduzidos de Seikkula e colaboradores (Seikkula et al., 2007a, 2007b) que contribuíram para dar mais visibilidade à abordagem do Diálogo Aberto. Também nesse período, trouxemos Jaakko Seikkula pela primeira vez para um Workshop em São Paulo ${ }^{7}$, num evento organizado pelo Instituto Familiae com apoio da Unifesp. Embora há dez anos a abordagem do Diálogo Aberto fosse ain-
${ }^{5}$ Escola Paulista de Medicina, que a partir de 1997 passou a integrar a Universidade Federal de São Paulo.

${ }^{6} 0$ Modelo do Recovery na Saúde Mental é um enquadre de referência para os percursos de recuperação e superação pessoais nos transtornos mentais. Baseado nos conceitos de esperança, rede de apoio, corresponsabilidade e empoderamento, o Recovery também orienta, em alguns países, políticas e práticas atuais de saúde mental que acoIhem 0 diálogo e estimulam a parceria entre profissionais e as pessoas que buscam ajuda e tratamento nos serviços de saúde mental.

${ }^{7}$ Workshop: "Diálogos abertos com famílias e redes sociais: Presença para gerar diálogo organizando o sistema para que todos sejam ouvidos", com Jaakko Seikkula, organizado pelo Instituto Familiae no CAPS Luiz da Rocha Cerqueira, São Paulo, em 22 e 23 de março de 2010). 
da bastante desconhecida por aqui, o evento chamou atenção de profissionais da rede pública de saúde mental e deixou em todos os que participaram o desejo de conhecer mais e continuar a conversar.

Se não consegui levar para a clínica do Programa de Esquizofrenia da Unifesp uma prática que incluísse as famílias desde o início do tratamento, sei que ao menos pude abrir caminho para que a perspectiva do Modelo do Recovery, em muitos sentidos afinada com os princípios das práticas colaborativas e dialógicas, tenha sido reconhecida pelos meus pares e iniciativas a partir dessa perspectiva tenham ganhado visibilidade e respeito no serviço. Estas ações certamente me mantiveram engajada e motivada nos últimos 20 anos na Universidade. Posso dizer mesmo que, através delas, me mantive curiosa, interessada, esperançosa e estimulada a buscar alternativas, ainda que um tanto marginais a princípio, de construir um percurso de práticas colaborativas no seio de um serviço psiquiátrico convencional. Hoje percebo também que, se não pude criar uma prática terapêutica afinada com os princípios do Diálogo Aberto no PROESQ, o desejo não realizado me impulsionou a buscar uma segunda formação em terapia familiar para levar esse modelo de atenção integrada às famílias para o sistema de saúde mental.

\section{APRENDENDO A CAMINHAR NA TRILHA DO DIÁLOGO ABERTO}

Iniciar um novo caminho de formação em 2017 devolveu-me o instigante, criativo e por vezes desconfortável lugar de aprendiz. Voltei a me fazer as perguntas que todo terapeuta recém-formado se faz, por exemplo: ao praticar, não estou acessando a teoria, mas centrada nos meus clientes, em suas questões e nas minhas perguntas e respostas às suas questões? Como se dá o processo de escolher o que dizer e o que propor em cada momento de interação? Por que escolho um caminho e não outro? O que gerou movimento ou mudança a partir dessa interação? Como eu percebo e decido o que fazer e falar no contexto de um atendimento? Por que determinadas ações se tornam terapêuticas?

Logo foram surgindo outras questões, pois quase ao mesmo tempo que voltei a ser aprendiz de terapeuta, formei um grupo de estudos e práticas no Instituto NOOS/SP e a responsabilidade de coordenadora e mentora me levou a refletir também sobre a complexidade da questão de ensinar-aprendendo essa mesma prática junto aos colegas terapeutas de família. Às perguntas de aprendiz de terapeuta somaram-se aquelas da formadora, por exemplo: como traduzir em aprendizado para outros o que se passa no contexto singular de uma prática terapêutica? Como criamos e sustentamos um bom contexto de aprendizado colaborativo? Como ensinar o que só se aprende fazendo?

Algumas ideias do filósofo Donald Schön têm sido norteadoras em meus processos de aprendizado, prática e reflexão na vida. Este filósofo e professor dedicou décadas de estudo às questões do processo de aprendizagem e da eficácia profissional. Iniciando sua investigação a partir de um estudo sobre a formação dos arquitetos, pôs-se a observar como estes criavam seus projetos. Olhando para o processo através do qual construíam algo com os materiais de que dispunham, o que acontecia quando abandonavam um projeto, como superavam barreiras, como lidavam com os erros e com 
as surpresas, foi percebendo que a complexidade das ações do trabalho do profissional era muito difícil de ser traduzida em explicações verbais, e as teorias que serviam de base a esses profissionais não se encaixavam muito bem na prática. Dessa pesquisa inicial com arquitetos, Schön foi estudar, através de conversas reflexivas, professores, e depois terapeutas. E então concluiu que todos nós temos um conhecimento tácito, implícito, presente nas ações habituais - um "conhecimento na ação" (Schön, 2000, p. 32). Nós não o acessamos a todo momento, mas o utilizamos tanto quando, por exemplo, cozinhamos ou andamos de bicicleta, como quando praticamos uma profissão. Entretanto, podemos pensar criticamente sobre esse conhecimento a partir da "reflexão-na-ação" (Schön, 2000, p. 33). Este saber a partir de uma situação pode ser descrito também como um conhecimento "encarnado", através, por exemplo, das mãos e dos olhos.

Rubem Alves tem uma frase linda que diz mais ou menos o mesmo, e fala profundamente à minha alma de terapeuta ocupacional:

Embora isso esteja esquecido, o caminho para a inteligência passa pelas mãos. Pensamos para ajudar as mãos. Das mãos nascem as perguntas. Da cabeça nascem as respostas. Se a mão não pergunta, a cabeça não pensa. (Alves, 2002, p. 3)

"Fazer com as mãos" foi sempre um valor importante na minha família. Tive a felicidade de crescer com recursos e ter tido muito incentivo de meus pais para explorar novas linguagens e aprender diversas atividades manuais, artísticas e musicais. Essas experiências constituíram uma bagagem importante e certamente guiaram a minha escolha profissional. Quando ainda estava na escola, já me interessava pelas questões relativas à saúde/doença mental, e as pessoas com quem eu convivia reconheciam em mim um 'jeito' para lidar com gente que me ajudou a definir a escolha da profissão. Cogitei fazer medicina, já pensando em psiquiatria, namorei a ideia de estudar psicologia, mas acabei me decidindo pela terapia ocupacional, uma profissão pouco conhecida (até hoje), pois me encantava a possibilidade de desenvolver um trabalho terapêutico através de atividades.

Apesar de ter escolhido trabalhar com a doença e o sofrimento, desde o princípio o meu encontro com esse universo foi orientado pela possibilidade de entender a experiência e os sentidos da dor das pessoas, buscando contribuir para a construção de vínculos, competências e narrativas alternativas, através das possibilidades e da criatividade geradas no processo do fazer atividades no contexto de uma relação terapêutica. O raciocínio clínico em terapia ocupacional é um raciocínio narrativo: contamos e criamos histórias prospectivas, entendendo o processo terapêutico enquanto um "conto" dentro de uma narrativa maior. Nesse sentido, a terapeuta ocupacional que me habita continua a pensar a atuar junto com a terapeuta familiar que me tornei.

Voltando a Schön e à relevância de suas ideias em meu percurso de aprendizado, prática e ensino - uma das conclusões importantes de seus estudos foi a constatação de que os profissionais fazem uso de dois grandes grupos de teorias para orientar sua prática: um, o conjunto de premissas que formam o que denominamos 'teorias científicas'. Pakman, tecendo aproximações com as ideias de Schön, as chamou de "as teorias que desposamos" 
(Pakman,1999, p. 24). Essas são as teorias que aprendemos na sala de aula e escolhemos para informar nossa prática. O outro grupo, das "teorias em uso, ou da ação" (Pakman,1999, p. 24), é constituído pelas experiências e relações pessoais, contexto cultural, econômico e político em que se vive, momento ou etapa de vida, enfim, todos aqueles elementos para os quais as disciplinas formais não dão conta. Uma diferença importante entre esses dois grupos de teorias é que o segundo é caracterizado pela instabilidade, ou seja, nunca se sabe a priori quais elementos vão ser úteis, quais vão ser necessários, o que vai ser limitante.

Estas ideias de Schön e de Pakman conversam com as de um grande pensador da dialogia - John Shotter, quando este propõe o conceito de "conhecimento do terceiro tipo" (Shotter, 2008, p. 41) para descrever o tipo de conhecimento que está presente apenas no aqui-agora das interações entre as pessoas - um conhecimento conjunto, intersubjetivo, um saber-com-o-outro, compartilhado. Shotter também afirma que é um conhecimento corporificado (ou encarnado) - sua natureza escapa à descrição por meio de palavras apenas, é mais uma atividade do que uma coisa. (Shotter, 2008, p. 41).

Em abril de 2017 um artigo seu, originalmente publicado em 2009, foi traduzido e publicado na Nova Perspectiva Sistêmica (NPS, 57, 2017). Shotter havia falecido poucos meses antes, e os textos publicados na NPS me conectaram ao sentimento de reverência a alguém cuja produção acadêmica, erudição e generosidade para dialogar foi marcante para as pessoas com quem se encontrou e interagiu na vida. Relendo o texto para compor este artigo, me emocionei também com a lembrança de aprender com as suas apresentações tão ricas em poesia e afeto, um apren- dizado emocionado, que me tocou e transformou pelo convite a valorizar a presença, a espontaneidade e a transparência no encontro terapêutico. Por isso, transcrevo aqui a pergunta inicial de Shotter nesta publicação de 2017:

O que é que, em nossa interação com os outros, não apenas torna a psicoterapia possível, mas também, em muitos outros casos cotidianos, abre-nos uma possibilidade de sermos profundamente transformados em nossos encontros com os outros e com a alteridade que nos rodeia, ou seja, muda nosso 'modo' de pensar, o 'modo' de ver e ouvir, os 'modos' de conectarmos eventos, 'modo' de falar etc. - enfim, mudanças do tipo de pessoa que somos? (Shotter, 2017, p.10)

E em consonância com Guanaes-Lorenzi, compartilho sua reflexão: "imagino retratar também a inquietação de muitos profissionais que, de alguma forma, trabalham com relações humanas e processos de mudança" (2017, p. 117). Inquietação e tensão também fazem parte desse estar-com-o-outro-em-diálogo.

Jaakko Seikkula inicia alguns de seus textos (Seikkula, 2008, 2011) com a afirmação: "participar num diálogo é a primeira coisa que aprendemos ao nascer, e tornamo-nos humanos através da intersubjetividade vivenciada em diálogos". E em seguida nos pergunta: "por que então é tão difícil dialogar?" (Seikkula, 2011, p. 179) ${ }^{8}$.

Rober (2017) responde: porque há sempre tensão no diálogo. E especificamente no contexto das relações terapêuticas, há a inescapável violência que ronda a tensão entre o imperativo ético na prática concreta da hospitalidade $^{9}$. Como terapeutas, não podemos escapar de fazer certas perguntas e de 
sermos violentos com essas perguntas, apesar das nossas melhores intenções. Quando trabalhamos com pessoas em crise, comumente nos deparamos com histórias de colapso do diálogo. A psicose, enquanto uma resposta a vivências para as quais não há (ainda) palavras, também nos apresenta um desafio na construção de um diálogo. Encontramo-nos com pessoas em grande sofrimento, solidão, desconfiança, desânimo, desesperança e desespero. Trabalhamos a partir de histórias de abuso, abandono e violência. Diante dessas situações, quais valores e "teorias da ação" cada um de nós traz para o encontro terapêutico, com que emoções construímos um movimento de encontro para deixar surgir, acolher, restaurar o diálogo em circunstâncias às vezes tão delicadas ou extremas? Quais valores embasam as nossas ideias sobre laços familiares, problema de saúde mental, limites, recursos pessoais, e como estão presentes quando começamos uma conversa com as pessoas que buscam tratamento em nossos serviços de saúde mental?

Estas são algumas perguntas que me guiam nessa prática, e que me lembram diariamente da necessidade de me manter aprendiz. Já afirmei neste texto que o amor é um fio condutor presente nas relações que estabeleço com pacientes, colegas e alunos - amor manifesto através da intenção de escutar atentamente, generosamente, de testemunhar compassivamente (Weingarten, 2016), de responder a partir de ressonâncias positivas, e amor marcando pontos de virada no processo de cura (Seikkula \& Trimble, 2005). E também, o amor como referência para momentos generativos e de transformação, vivenciados na prática e na leitura de textos inspiradores aos quais voltei muitas vezes meu percurso de formação e prática clínica.
Ainda neste texto quero dar espaço para outro guia importante na minha prática e ensino/aprendizado, a esperança. Construí meu percurso profissional trabalhando com pessoas sobre as quais se depositam os piores julgamentos, os assim chamados "loucos" - aqueles por quem poucos sentem compaixão e vontade de estar perto. E talvez respondendo à carga negativa do estigma da loucura, desenvolvi ao longo dos anos uma postura de resistência e confronto perante este discurso que enquadra as pessoas numa categoria tão marginal. Hoje sei que essa postura foi muito sustentada pela esperança, a mesma que tem sido o motor de outras iniciativas na minha vida e está inscrita na textura das relações que procurei desenvolver com cada paciente que atendi e com cada profissional/aluno que contribuí para formar. Em cada uma dessas relações eu aprendi algo sobre mim e sobre o mundo.

Por isso voltei a ler, no processo de escrever este texto, o livro "Conversas com quem gosta de ensinar", de Rubem Alves. Sua escrita poética, reflexiva e irreverente sempre me cativou e, nesse livro em particular, provoca a pensar sobre o que é ser um educador. Nos pergunta Alves no primeiro capítulo do livro - Sobre Jequitibás e Eucaliptos: Amor:

Educadores, onde estarão? Em que covas terão se escondido? Professores, há aos milhares. Mas professor é profissão, não é algo que se define por dentro, por amor. Educador, ao contrário, não é profissão; é vocação. E toda vocação nasce de um grande amor, de uma grande esperança. (Alves, 1988, p. 15) 
E continua, um pouco mais adiante:

Pode ser que educadores sejam confundidos com professores, da mesma forma como se pode dizer: jequitibá e eucalipto, não é tudo árvore, madeira? No final, não dá tudo no mesmo? Não, não dá tudo no mesmo, porque cada árvore é a revelação de um habitat, cada uma delas tem cidadania num mundo específico. Eu diria que os educadores são como as velhas árvores ... Habitam um mundo em que o que vale é a relação que os liga aos alunos, sendo que cada aluno é uma "entidade" sui generis, portador de um nome, também de uma "estória", sofrendo tristezas e alimentando esperanças. E a educação é algo pra acontecer neste espaço invisível e denso, que se estabelece a dois. Espaço artesanal. (Alves, 1988, p. 15)

'Espaço artesanal' é uma linda metáfora para o delicado bordado relacional de aprender-ensinar-cuidar em saúde mental. Encanta-me pensar que somos artesãos de relações e de diálogos potencialmente transformadores. Peço, então, licença poética a Rubem Alves, para dizer que o que tentei com meu texto até aqui foi convidá-los também a uma 'conversa com quem gosta de aprender'.

\section{SEGUINDO O CAMINHO: CONFIAR, ESCUTAR, INVENTAR, ARRISCAR E CRIAR CONJUNTAMENTE}

Aprendi desde cedo, nas viagens com meu pai, que é sempre possível procurar um caminho diferente do que fizemos na ida a algum lugar. Isso rendeu algumas experiências de nos perder em trilhas e estradas desconhecidas e não sinalizadas, mas também o prazer de descobrir caminhos inusitados. Estas experiências me marcaram positivamente porque eu sabia que podia confiar em meu pai. Aprendi também com essas aventuras que, cuidando de certos parâmetros, podíamos nos arriscar. Essa postura, de alguma forma, eu tenho levado aos meus projetos de vida.

Com isso, percebo que venho trilhando estradas diversas há muitos anos - fui pela trilha da arteterapia, enveredei pela antropologia, encontrei o caminho da terapia familiar sistêmica, e por ele cheguei às práticas dialógicas. Se em alguns momentos eu me vi em encruzilhadas, a experiência de já ter antes entrado em um novo terreno sempre me ajudou a não perder a orientação e achar o caminho de casa. A casa, aqui na minha metáfora, é o trabalho de terapeuta-formadora na saúde mental. O Diálogo Aberto foi o caminho que, vislumbrei, poderá aproximar as minhas experiências de atuar e ensinar como terapeuta ocupacional e terapeuta familiar na saúde mental, para construir uma comunidade integrada de profissionais em torno de práticas colaborativas com famílias na saúde mental.

Uma das premissas principais do Diálogo Aberto é não estabelecer um limite definido entre reunião de planejamento de tratamento e tratamento/ terapia propriamente dito. Os encontros respeitam um formato pré-definido, principalmente pelas perguntas de abertura, mas a proposta é criar condições para uma conversa entre todos. Em minha experiência como terapeuta familiar, muitas vezes senti que as 'ferramentas' que trazia de meu fazer como terapeuta ocupacional continuavam úteis, embora inicialmente eu costumasse me perguntar se seria adequado usá-las, pois poderia parecer que eu estaria trajando um 'vestido 
velho' numa festa onde devia usar uma roupa nova. Pouco a pouco, porém, esta metáfora da roupa nova/velha foi perdendo o sentido, porque ao me tornar mais fluente em conversar com famílias na prática clínica e nos diversos projetos e grupos que desenvolvemos na $A B R E$, entendi que muito mais do que uma roupa, eu praticava um jeito de sentir, ser e estar com as pessoas, aprendendo a simplesmente ser com o outro. Só mais tarde fui aprender o termo "withness thinking" (Shotter, 2006), entendendo que o caminho para este tipo de compreensão responsiva, corporificada, fluida e espontânea só é acessível nas relações dialógicas. Isso fez sentido imediato e falou ao coração. O Diálogo Aberto é o caminho do coração aberto para aprender com o outro, começando por praticar a ouvir mais, silenciar mais, conectar-se e responder com o corpo e as emoções para seguir cuidadosa e respeitosamente a história e o tempo do outro, sem apressar compreensões, acordos e decisões.

\section{CONCLUINDO}

\section{Inspirada em Tom Andersen, sempre}

Parece que apenas começamos a fazer algo que é suficientemente simples para ser viável, suficientemente criativo para ser útil, suficientemente pequeno para ser transportável e suficientemente repleto de surpresas inesperadas que mantêm viva nossa própria curiosidade. (Andersen, 1996, p. 109)

Para concluir, queremos ${ }^{10}$ levantar algumas questões a partir da prática que iniciamos em 2018 no Noos e no GAPi/Unifesp, numa equipe compos- ta por profissionais com experiência em graus variados em práticas colaborativas e reflexivas no contexto das terapias de família. Temos nos deparado com o desafio de aprender, como brincamos às vezes, a nos tornar 'finlandeses. Alguns desafios e questões dizem respeito a praticar uma escuta corporificada, atenta ao momento presente, seguindo o fluxo da conversação ao mesmo tempo que cuidamos de manter um formato que inclua as perguntas de abertura - "Qual a história da ideia deste encontro?" e "Como cada um quer usar este espaço hoje?”. Também estamos aprendendo a estar mais atentos e responder usando as palavras de nossos clientes e colegas, a não explicar as nossas perguntas, a buscar contribuir para incentivar a polifonia e cuidar que as nossas reflexões sejam breves e focadas no que ouvimos, sentimos e o que queremos oferecer para a continuidade da conversa.

Nas muitas horas de conversas e supervisões, revendo as gravações dos atendimentos, nas leituras e discussões, ao aprender com nossos erros, temos levantado questões, para o presente e o para o futuro, que partilhamos como conclusão deste texto num convite aos que desejarem seguir conversando conosco. Algumas questões dizem mais respeito a aprender/ensinar esta maneira de estar na prática; outras são questionamentos e desafios mais estruturais para pensar as possibilidades de multiplicar e adaptar o Diálogo Aberto no Brasil.

Queremos entender mais sobre como aproximar as práticas colaborativas e dialógicas que sabemos afinadas com o Diálogo Aberto, por exemplo, a Terapia Comunitária, as diversas iniciativas de fortalecimento e articulação de redes de solidariedade e apoio, e as iniciativas que contemplam o diálogo e a colaboração como
${ }^{10}$ Aqui escrevo no plural porque, junto com Flávia Camargo, Elvis Andrade, Roberto Costard e Denise Liesegang, formamos em 2019 o 'Núcleo de Atenção em Saúde Mental a Famílias do N00S', constituindo um grupo de prática, ensino e aprendizagem colaborativa e reflexiva, com atividades regulares tanto no Instituto NOOS como no GAPi - Grupo de Atenção às Psicoses Iniciais da Unifesp. 
posturas para práticas na rede de saúde mental e nas estratégias de saúde da família. Foge ao escopo deste texto elencar e discutir as aproximações do Diálogo Aberto com estas práticas, mas seguramente este é um caminho a ser percorrido no futuro próximo, e artigos publicados recentemente por colegas interessados na abordagem do Diálogo Aberto já abriram perguntas nesse sentido (Florence, 2017; Kantorski \& Cardano, 2017). As nossas questões, entretanto, vêm principalmente da prática e, nesse sentido, esperamos que venham compor com os questionamentos já delineados nos textos nacionais de apresentação dos princípios do Diálogo Aberto.

Para fechar este texto, convidando a continuar esta conversa, perguntamos:

- Quais as convergências entre as abordagens do Diálogo Aberto e do Projeto Terapêutico Singular (PTS) podem ocorrer na RAPS/SUS? São propostas possíveis de serem integradas nos serviços de saúde mental? Que mudanças institucionais serão necessárias, onde e como podemos começar a propor essa aproximação?

- A formação dos profissionais de saúde mental geralmente não contempla uma postura sistêmico-relacional e a diferença na formação aumenta a complexidade e dificuldade de trabalhar seguindo os princípios de dialogia, transparência e tolerância à incerteza. Como poderemos fomentar a formação de profissionais para trabalhar em abordagens dialógicas com famílias e redes?

- Algumas experiências de atendimento no GAPi/Unifesp têm mostrado que o profissional da equipe que entra conosco nos atendimentos para conhecer e participar de um atendimento parece sair com mais esperança e curiosidade em relação à família atendida. Como criar mais conversas reflexivas sobre a experiência desta prática com esses profissionais num sistema que não contempla espaços de reflexão?

- Talvez pelas dificuldades de acesso aos serviços de saúde, muitas pessoas que buscam tratamento já vêm vivenciando crises que não são recentes nem brandas. Quanto isso dificulta uma prática dialógica efetiva? Como poderemos criar condições dentro da estrutura de um serviço público para desenvolver mais agilidade para atender mais rapidamente a situações de crise?

- Pensando na dificuldade de praticar num ritmo e tempo mais lentos, sobre falas sobrepostas e sem pausa e falta de espaço para o silêncio nas conversas: quanto de cultural há nesse jeito de estar com as pessoas que é tão diferente do ritmo finlandês?

Em seu texto "Celebração da surpresa", refletindo sobre a curiosidade na prática clínica e investigando os sentidos de conexão, Fuks (2011) pergunta sobre que formas relacionais são estas que chamamos conexões (p. 91) e propõe que se conectar é uma posição relacional que pressupõe transparência, um interesse genuíno pelo outro, e estar "posicionado na $1^{\text {a }}$ pessoa sem se proteger atrás de uma técnica” (p. 91). Conectar-se, qualificado dessa manei- 
ra, tem ressonância com uma forma de relação descrita por Shotter (2107), fazendo referência a Bakhtin, como um momento dialógico. Nós temos vivenciado transformações propiciadas pelos momentos dialógicos nesta comunidade de aprendizagem que constituímos para aprender e praticar o Diálogo Aberto, e queremos seguir caminhando de coração aberto por esta trilha, com quem mais quiser se juntar a nós.

\section{REFERÊNCIAS}

Alanen, Y. O. (1997). Schizophrenia: its origins and need-adapted treatment. London: Karnac.

Alanen, Y. O. (2009). Towards a more humanistic psychiatry: Development of need-adapted treatment of schizophrenia group psychoses, Psychosis, 1(2), 156-166. doi:10.1080/17522430902795667.

Alves, R.(2002, 21 de julho). As mãos perguntam, a cabeça pensa. Folha de São Paulo, Tendências/Debates, p.3. Recuperado de https:// www1.folha.uol.com.br/fsp/opiniao/ fz2107200208.htm

Alves, R. (1980). Conversas com quem gosta de ensinar.São Paulo: Cortez.

Andersen, T. (1996). Processos Reflexivos. Rio de Janeiro: NOOS.

Assis, J. C. \& Villares, C.C. (2006). Serviço de orientação à esquizofrenia. In S.M. Malta, C. Attux,\&R.A. Bressan (Eds.), Esquizofrenia: integração clínico-terapêutica (pp. 167-181). São Paulo: Atheneu.

Bergström, T.s, Seikkula, J., Alakare, B., Mäki, Pu, Köngäs-Saviaro, P, Taskila, J. J. et al.(2018). The family-oriented open dialogue approach in the treatment of first-episode psychosis: nineteen-year outcomes. Psychiatry Research, 270, 168-175. Recuperado de https://www.scien- cedirect.com/science/article/abs/pii/ S0165178117323338?via\%3Dihub. doi:10.1016/j.psychres.2018.09.039.

Florence, A. C. (2018). A abordagem Open Dialogue: história, princípios e evidências. Polis e Psique, 8(1), 191211.Recuperado de https://seer.ufrgs. br/PolisePsique/article/view/80427/ pdf. doi:10.22456/2238-152X.80427.

Fuks, S. (2011). Celebração da surpresa. Nova Perspectiva Sistêmica, 20(41),85-98.

Guanaes-Lorenzi, C. (2017). Comunicação dialógica: ecos e movimento. Nova Perspectiva Sistêmica, 26(58), 117-120.

IGDA/WPA. (2003). Essentials of the World Psychiatric Association's International Guidelines for Diagnostic Assessment (IGDA). British Journal of Psychiatry, 182(45), 37-66.

Kantorski, L. P. \& Cardano, M. (2017). Diálogo Aberto: a experiência finlandesa e suas contribuições. Saúde Debate, 41(112), 2332. Recuperado de http://www. scielo.br/pdf/sdeb/v41n112/01031104-sdeb-41-112-0023.pdf. doi:10.1590/0103-1104201711203.

Miranda, A. P. M., Villares, C. C., \& Pimentel, F. A. (2014).Anjos de uma asa só: processos de superação na esquizofrenia em um grupo de ajuda mútua. Nova Perspectiva Sistêmica,23(48), 64-79.

Olson, M. (2015). An auto-ethnographic study of "Open Dialogue:" the illumination of snow. Family Process, 54(4), 716-729. doi:10.1111/famp.12160.

Olson, M., Seikkula, J., \& Ziedonis, D. (2014). The key elements of dialogic practice in open dialogue: fidelity criteria.The University of Massachusetts Medical School. Worcester, MA. Recuperado de https://medschool. ucsd.edu/som/psychiatry/research/ open-dialogue/Documents/keyelementsv1.109022014.pdf 
Pakman, M. (1999). Desenhando terapias em saúde mental comunitária: poética e micropolítica dentro e além do consultório. Nova Perspectiva Sistêmica, 8(13), 6-25.

Rober, P. (2017). In therapy together: family therapy as a dialogue. London: McMillan.

Rober,', Pu \& De Haene, L. (2017). Hospitality in family therapy practice: afurther engagement with Jacques Derrida. Australian and New Zealand Journal of Family Therapy,38(3), 378-390. doi:10.1002/anzf.1254.

Schön, D. (2000). Educando o profissional reflexivo: um novo design para o ensino e a aprendizagem. Porto Alegre: Artmed.

Seikkula, J. (1994). When the boundary opens: family and hospital in co-evolution. Journal of Family Therapy, 16(4), 401-414. doi:10.1111/j.14676427.1994.00805.x.

Seikkula, J. (2008). Inner and outer voices in the present moment of family and network therapy. Journal of Family Therapy, 30(4), 478-449. doi:10.1111/j.14676427.2008.00439.x.

Seikkula J. (2011). Becoming dialogical: psychotherapy or a way of life? The Australian and New Zealand Journal of Family Therapy, 32(3), 179-193. Recuperado de https://www.taosinstitute.net/Websites/taos/files/Content/5695642/becoming-dialogiical. pdf. doi:10.1375/anft.32.3.179.

Seikkula J. (2017). Tornando-se dialógico: psicoterapia oumodo de vida? In M. A. Grandesso (Org.),Práticas colaborativas e dialógicas em distintos contextos e populações: um diálogo entre teoria e práticas (pp. 35-55). São Paulo: Editora CRV.

Seikkulla, J., Aaltonen, J., Alakare, B., Haarakangas, K., Keränen, J., \& Sutela, M. (1995). Treating psychosis by means of open dialogue. In S.
Friedman (Ed.), The reflective team in action (pp. 62-80). New York: Guilford Press.

Seikkula, J., Alakare, B., Aaltonen, J., Holma, J., Rasinkangas, A.s \& Lehtinen, V. (2003). Open dialogue approach: treatment principles and preliminary results of a two-year follow-up on first episode schizophrenia. Ethical Human Sciences and Services, 5(3), 163-182.

Seikkula, Jus, Alakare, Bus, Aaltonen J.s Haarakangas, K., Keränen, J., \& Lehtinen, K. (2006). Five years experiences of first-episode non-affective psychosis in Open Dialogue approach: Treatment principles, follow-up outcomes and two case analyses. Psychotherapy Research, 16(2), 214-228. doi:10.1080/10503300500268490.

Seikkula, J, Alakare, B., \& Aaltonen, J. (2007a).Diálogos abertos em psicose, parte 1: introdução e relato de um caso. Nova Perspectiva Sistêmica, 27, 20-37.

Seikkula, J, Alakare, Ba, \& Aaltonen, J. (2007b).Diálogos abertos em psicose, parte 2: uma comparação de casos com resultados bons e ruins. Nova Perspectiva Sistêmica, 28, 54-67.

Seikkula, J., Karvinen, A., Kykyrí, V Penttonen, M., \& Nyman-Salonen, P. (2018). The Relational mind in couple therapy: a Bateson-inspired view of human life as an embodied stream. Family Process, 57, 855-866. doi:10.1111/famp.12382.

Seikkula, J. \& Olson, M. (2003). The open dialogue approach to acute psychosis: its poetics and micropolitics. Family Process, 42, 403-418.doi:10.1111/ j.1545-5300.2003.00403.x.

Seikkula, J.\& Trimble, (2005). Healing elements of therapeutic conversation: dialogue as an embodiment of love. Family Process, 44(4), 461-475. doi:10.1111/j.15455300.2005.00072.x. 
Shotter, J. (2006). Understanding process from within: an argument for 'withness'-thinking. Organization Studies, 27(4), 585-604. Recuperado de https://www.researchgate.net/ publication/247734533 Understanding_Process_From_Within_An Argument for 'Withness'Thinking. doi:10.1177/0170840606062105.

Shotter', J. (2008). Conversational realities revisited: life, language, body and world. Ohio: Taos Institute.

Shotter', J. (2017). Momentos de referência comum na comunicação dialógica: uma base para a colaboração em contextos únicos. Nova Perspectiva Sistêmica, 57(1), 5-8.

Villares, C.C. (2000). Adaptação transcultural de intervençõespsicossociais na esquizofrenia. Revista Brasileira de Psiquiatria, 22 (Supl.1), 53-55. Recuperado de http://www.scielo. br/scielo.php?script=sci arttext\&pi $\mathrm{d}=$ S1516-44462000000500018. doi: 10.1590/S1516-44462000000500018.

Villares, C.C. (2001). Orientação familiar na Esquizofrenia. In M. Grandesso (Org.), Terapia e Justiça Social (pp. 260-268). São Paulo:APTF. Villares, C.C. (2006a). Seminários informativos. In S.M. Malta, C. Attux,\& R.A. Bressan (Eds.), Esquizofrenia: integração clínico-terapêutica (pp. 63-72). São Paulo: Atheneu.

Villares, C.C. (2006b). A criatividade como postura em ações para gerar transformação social. Nova Perspectiva Sistêmica, 26, 65-75.

Villares, C.C. (2008). Ecos: Como contribuímos para a recuperação de pessoas com transtornos mentais graves? Nova Perspectiva Sistêmica, 31, 99-101.

Villares, C.C. (2012). Abordagem familiar na esquizofrenia. In C. S. Noto \& R. A. Bressan, (Orgs.), Esquizofrenia: Avanços no Tratamen- to Multidisciplinar (pp. 251-265). São Paulo: Artmed.

Villares, C. C., Pimentel, F. A., Assis, J. C., \& Orsi, J. A. (2013). Associações de usuários e familiares e estratégias para defesa dos direitos dos portadores de transtorno mental. In M.D. Mateus (Org.),Políticas de Saúde Mental (pp.76-91). São Paulo: Instituto de Saúde.

Villares, C. C. \& Pimentel, F. A. (2015). Collaborative processes can create social change in schizophrenia. In E. Rasera (Ed.),Social perspectives on group work (pp 91-100). Ohio: Taos Institute.

Von Peter, $S_{n}$, Aderhold, V., Cubellis, L., Bergström, T., Stastny, P., Seikkula, Ja, \& Puras, D. (2019). Open dialogue as a human rights-aligned approach. Frontiers inPsychiatry 10,387.Recuperado de https://www.frontiersin.org/articles/10.3389/fpsyt.2019.00387/full. doi:10.3389/fpsyt.2019.00387.

Weingarten, K. (2016). The art of reflection: turning the strange into the familiar. Family Process,55(2),195-210. doi:10.1111/ famp. 12158

\section{CECÍLIA CRUZ VILLARES}

É terapeuta ocupacional pela FMUSP/SP; mestre em Saúde Mental pela Escola Paulista de Medicina da Unifesp. Associada efetiva e membro da Clínica do Instituto NOOS, São Paulo; Diretora-presidente da ABRE - Associação Brasileira de Familiares, Amigos e Portadores de Esquizofrenia, São Paulo/SP.

E-mail: civillares@gmail.com 